\title{
Extrato de tingui na conservação da tilápia-do-Nilo
}

\author{
Tingui extract in conservation of Nile tilapia
}

\author{
MIRANDA, Aline Dayane Lopes ${ }^{1}$; DELVAUX JÚNIOR, Nelson Abreu ; AIURA, \\ Felipe Shindy $^{1 *}$; AIURA, Auriclécia Lopes de Oliveira ${ }^{1}$; MACIEL, Mônica Patrícia ${ }^{1}$; \\ AROUCA, Cláudio Luiz Corrêa ${ }^{1}$
}

\begin{abstract}
${ }^{1}$ Universidade Estadual de Montes Claros, Centro de Ciências Exatas e Tecnológicas, Departamento de Ciências Agrárias, Janaúba, Minas Gerais, Brasil.

*Endereço para correspondência: fsaiura@gmail.com
\end{abstract}

\section{RESUMO}

O objetivo foi avaliar o extrato de tingui aplicado previamente ao abate nas alterações post mortem da tilápia-do-Nilo. Utilizou-se 72 exemplares de tilápia-do-Nilo com peso médio de $527 \pm 53 \mathrm{~g}$. Os peixes foram distribuídos aleatoriamente em 12 caixas com capacidade de 50 litros cada, às quais foram adicionadas três soluções de acordo com os tratamentos, extrato de tingui hidroalcoólico; extrato de tingui aquoso e cloro, formando um delineamento inteiramente casualizado com três tratamentos e quatro repetições. Os peixes permaneceram nas caixas durante 40 minutos e após esse período eles foram colocados em caixas isotérmicas contendo água e gelo (1:1) para a insensibilização e abate. Posteriormente, os peixes foram acondicionados em bandejas plásticas, contendo gelo em camadas. $\mathrm{O}$ período de armazenamento foi de 21 dias. Foram avaliados, o rigor mortis, $\mathrm{pH}$, bases nitrogenadas voláteis totais (BNVT) e a análise sensorial. O rigor mortis dos peixes atingiu plenitude após 14 horas de armazenamento em todos os tratamentos. $\mathrm{O}$ tratamento com extrato de tingui aquoso se mostrou mais eficiente, evitando que o pescado sofresse alterações de pH e BNVT durante 21 dias de armazenamento, além de ser melhor aceito sensorialmente.

Palavras-chave: armazenamento, gelo, Magonia pubescens, processamento

\section{SUMMARY}

The aim was to evaluate the tingui extract applied previously to slaughter about changes post mortem of Nile tilapia. Were used 72 Nile tilapia with average weight of $527 \pm 53 \mathrm{~g}$. The fishes were randomly distributed in 12 boxes of 50 liters each, which were added three solutions according to the treatments, hydroalcoholic tingui extract; aqueous tingui extract and chlorine, forming a completely randomized design with three treatments and four replications. The fishes remained in the boxes for 40 minutes and after this period, were placed in insulated boxes containing ice and water (1:1), for stunning and slaughter. After, the fish were packed in plastic trays containing ice layers. The storage period was 21 days. Were evaluated the rigor mortis, $\mathrm{pH}$, total volatile basic nitrogen (TVB-N) and sensory analysis. The rigor mortis of fishes reached fullness after 14 hours of storage for all treatments. The aqueous tingui extract treatment was the more efficient, preventing the fish suffer changes of $\mathrm{pH}$ and BNVT, during the storage by 21 days, besides being better accepted sensorily.

Keywords: storage, ice, Magonia pubescens, processing 


\section{INTRODUÇÃO}

Para atender as necessidades dos consumidores por pescado fresco de ótima qualidade é necessário que os processos de cultivo e principalmente os de captura, transporte e abate, sejam adequados.

O pescado é um alimento rico em proteínas, de fácil digestibilidade, baixo teor de gordura e rico em ácidos graxos do tipo ômega-3 (SILVA et al., 2008). Apesar desses benefícios o pescado é um alimento altamente susceptível à deterioração, devido a sua composição química e ao $\mathrm{pH}$ próximo à neutralidade, favorecendo o desenvolvimento microbiano (FRANCO \& LANDGRAF, 2008).

O processo de rigor mortis é muito importante na conservação do pescado, pois retarda a autólise após a morte e a decomposição bacteriana. Nos pescados, identificam-se três fases: pré-rigor mortis, rigor mortis e pós-rigor mortis. A duração da primeira fase depende das reservas de ATP e glicogênio no momento da morte, influenciadas diretamente pelo estresse sofrido nos manejos que antecedem o abate, e é de extrema importância que ela se prolongue ao máximo, preservando as características organolépticas e estendendo a vida útil do pescado conforme observado por Mendes et al. (2015). Segundo Contreras-Gusmán (1994), o estado de rigor mortis é definido como a perda de plasticidade e extensibilidade dos músculos. E na fase de pós-rigor mortis se iniciam os processos de degradação, caracterizado pela ação de enzimas proteolíticas, havendo o amolecimento da musculatura e formação de peptídeos, aminoácidos livres e aminas (OLIVEIRA, 2004).

Assim, substâncias naturais podem ser utilizadas com o intuito de minimizar o estresse no peixe durante o processo de abate, a fim de promover um prolongamento do pré-rigor e do rigor mortis, garantindo a manutenção da qualidade do pescado e oferecendo um produto de qualidade ao consumidor.

Diante disso, a Magonia pubescens, conhecida popularmente como tingui pode ser uma alternativa para minimizar o estresse durante o processo de abate e prolongar a vida do pescado fresco. A planta pode ser utilizada para limpeza de feridas em animais, como calmante e na pesca por meio da intoxicação da água, facilitando a captura dos peixes conforme relatado por Macedo et al. (2009). Pesquisas foram desenvolvidas utilizando o extrato de tingui no controle de insetos conforme Coelho (2006) e Silva et al. (2003), demonstrando que o extrato não se mostrou tóxico, possibilitando sua utilização com segurança.

Assim, o objetivo foi avaliar o extrato de tingui aplicado previamente ao abate nas alterações post mortem da tilápia-do-Nilo.

\section{MATERIAL E MÉTODOS}

O experimento foi realizado no Departamento de Ciências Agrárias da Universidade Estadual de Montes Claros - Campus Janaúba/MG e no Centro Integrado de Recursos Pesqueiros e Aquicultura do Gorutuba da Companhia de Desenvolvimento do Vale do São Francisco e Parnaíba - CODEVASF, no município de Nova Porteirinha/MG.

Utilizaram-se 72 exemplares de tilápiado-Nilo, linhagem GIFT, com peso médio de $527 \pm 53 \mathrm{~g}$. Os peixes foram capturados e selecionados de um viveiro de engorda, e posteriormente colocados em tanque de $10 \mathrm{~m}^{3}$, com renovação constante de água, por 48 horas para depuração.

Os peixes foram distribuídos em 12 caixas com capacidade de 50 litros cada, as quais foram preparadas com três 
soluções de acordo com os tratamentos: extrato de tingui hidroalcoólico; extrato de tingui aquoso e cloro. As concentrações utilizadas nas caixas foram de 4\% (v:v) para os extratos e de $5 \mathrm{ppm}$ para o cloro. Os peixes permaneceram dentro das caixas por 40 minutos. Após esse período os peixes foram colocados em caixas isotérmicas contendo água e gelo (1:1) para a insensibilização e abate. Posteriormente, os peixes inteiros foram acondicionados em bandejas plásticas, contendo gelo em camadas, envolvendo completamente os peixes. As bandejas foram colocadas em câmara fria a $4^{\circ} \mathrm{C}$, para evitar o derretimento excessivo do gelo, o qual era reposto periodicamente. O período de armazenamento foi de 21 dias.

Para a preparação dos extratos de tingui foi utilizada a casca fresca, retirada do tronco na árvore Magonia pubenses. Para o extrato hidroalcoólico foi colocado $100 \mathrm{~g}$ de casca em frasco graduado e adicionado álcool a $70^{\circ} \mathrm{GL}$ até completar volume de $1000 \mathrm{~mL}$. Esse frasco permaneceu em geladeira por 15 dias, sendo agitado e reposto o volume diariamente. Após esse período o extrato foi submetido à destilação fracionada sob pressão reduzida em aparelho de rotaevaporador. Para o extrato aquoso $100 \mathrm{~g}$ da casca foi desidratada em estufa a $45^{\circ} \mathrm{C}$ com ventilação forçada, triturada e colocada em água destilada estéril para completar o volume de $1000 \mathrm{~mL}$, sendo mantida sob fervura durante 20 minutos em aquecedor com refluxo. Após esses processos de preparação dos extratos, ambos foram filtrados e completados o volume com água destilada estéril, para $1000 \mathrm{~mL}$ do volume final.

O processo de aferição da instalação do rigor mortis iniciou-se logo após o abate, aferido a cada hora, estendendo-se por 14 horas. Para avaliação desse parâmetro utilizou um delineamento inteiramente casualizado em esquema fatorial $3 \times 14$ (três tratamentos e 14 tempos de avaliação), com quatro repetições. $\mathrm{O}$ índice de rigor foi calculado de acordo com a equação proposta por Bito et al. (1983): $\mathrm{IR}=[(\mathrm{Do}-\mathrm{D}) / \mathrm{Do}] \times 100$

Onde:

$\mathrm{IR}=$ Índice de rigor relativo (\%) Do $=$ valor da distância que separa a base da nadadeira caudal ao ponto de referência imediatamente após o abate.

$\mathrm{D}=$ valor da distância que separa a base da nadadeira caudal ao ponto de referência nos intervalos de tempos.

Para avaliação da conservação do pescado foram realizadas amostragens nos peixes durante os tempos de armazenamento 1, 7, 14 e 21 dias, para as análises de $\mathrm{pH}$, bases nitrogenadas voláteis totais (BNVT) e sensorial, utilizando-se um delineamento inteiramente casualizado, em esquema fatorial $3 \times 4$ (três tratamentos e quatro tempos de armazenamento), com quatro repetições.

$\mathrm{O}$ pH foi avaliado inserindo-se o eletrodo de um pHmetro digital na musculatura dorsal dos peixes. As BNVT foram determinadas em precipitação protéica com ácido tricloroacético e destilação com óxido de magnésio, conforme Howgate (1976) e o resultado expresso em $\mathrm{mg}$ de $\mathrm{N} / 100 \mathrm{~g}$ de músculo.

A análise sensorial foi realizada através do teste de aceitação de 30 julgadores não treinados, os quais receberam de maneira aleatória as amostras em recipientes devidamente codificados com números aleatórios, compostas de peixes inteiros sem processamento, representando os tratamentos, e uma ficha de avaliação para aferir os atributos aparência, cor, aroma e aceitação geral, utilizando a escala hedônica de nove pontos possuindo em seus extremos os termos: gostei muitíssimo (9) e desgostei muitíssimo (1), conforme modelo de Dutcosky (1996).

A análise estatística dos resultados foi realizada através de análise de variância, 
Rev. Bras. Saúde Prod. Anim., Salvador, v.17, n.4, p.763-771 out./dez., 2016 http://www.rbspa.ufba.br ISSN 15199940

sendo as médias dos tratamentos comparadas pelo teste de Scott Knott a $5 \%$ e as médias dos tempos de avaliação para o rigor mortis e os tempos de armazenamento para a conservação do pescado, submetidas ao estudo de regressão a 5\% de probabilidade por meio do programa SAS (1999),

\section{RESULTADOS E DISCUSSÃO}

$\mathrm{O}$ índice de rigor mortis nos peixes apresentou significância $(\mathrm{p}<0,01)$ para os tratamentos e tempo de armazenamento.
A implantação do rigor nos peixes foi crescente durante o tempo após o abate, atingindo sua plenitude após 14 horas de armazenamento para todos os tratamentos (Figura 1). No entanto, as tilápias que foram submetidas aos tratamentos com Tingui aquoso e Tingui hidroalcoólico apresentaram médias mais altas para rigor mortis, sendo 57,84 e $58,29 \%$ respectivamente, diferindo do tratamento com cloro $(53,99 \%)$. Entretanto, apesar dos peixes tratados com cloro apresentarem inicialmente um retardo no enrijecimento da musculatura, todos os peixes acabaram entrando em rigor pleno após 14 horas de armazenamento.

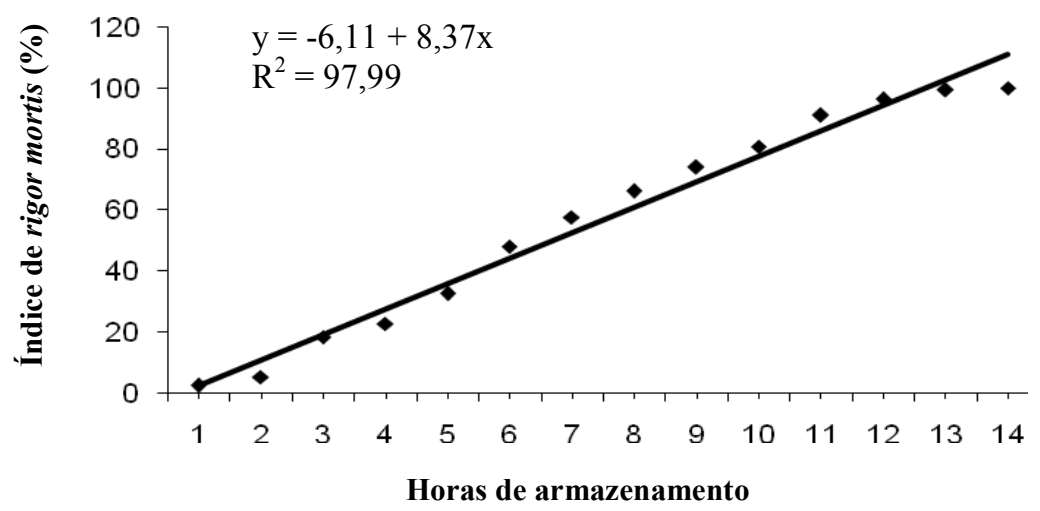

Figura 1. Médias para Índice de Rigor Mortis das tilápias-do-Nilo tratadas com cloro ou extrato de Tingui, armazenadas por 14 horas em gelo

Segundo Neiva (2002) é importante retardar a entrada do rigor mortis aumentando assim a vida útil do pescado, pois, após essa fase há o amolecimento da musculatura devido à hidrólise protéica e rápida ação dos microrganismos (OLIVEIRA, 2004).

Yasmin et al. (2001) avaliaram tilápias armazenadas em gelo e verificaram que o rigor mortis pleno foi atingido com três horas após a morte e que os peixes se mantiveram sensorialmente aceitáveis por 16 dias e rejeitados aos 18 dias de armazenamento. Em tilápias submetidas a dois tipos de abate, secção de medula e termonarcose, mantidas em gelo, apresentaram rigor pleno entre $8 \mathrm{e}$ 11 horas, não sendo influenciado pelo tipo de abate, conforme Pedrazzani et al. (2007).

$\mathrm{O}$ processo de abate pode interferir diretamente no tempo de implantação do rigor mortis, pois peixes que sofrem maior estresse durante esse processo, podem entrar em rigor mais rapidamente, afetando negativamente a qualidade do pescado e diminuindo a vida de prateleira (VIEGAS et al., 2012). Essa variação no 
tempo de implantação do rigor mortis pode também ser devido a diversos fatores extrínsecos, como a captura, a temperatura de estocagem e, principalmente, pela maneira como o peixe é sacrificado (BOYD et al., 1984, CONTRERAS-GUZMÁN, 1994).

$\mathrm{O} \mathrm{pH}$ no pescado foi influenciado $(p<0,01)$ pela interação entre os tratamentos e o tempo de armazenamento. De acordo com os resultados apresentados na tabela 1 , no período de 7 e 14 dias de armazenamento não houve diferença entre as médias para os tratamentos, sendo que aos 21 dias, os peixes que foram tratados com Tingui aquoso e cloro obtiveram valores menores de $\mathrm{pH}$ (Tabela 1).

Durante o período de armazenamento, apenas o tratamento hidroalcoólico apresentou diferença entre as médias, havendo uma diminuição no $7^{\circ}$ dia se mantendo até 14 dias de armazenamento, aumentando aos 21 dias. Aplicando-se o estudo de regressão para esse tratamento, pode-se observar a queda do $\mathrm{pH}$ dos peixes até um ponto estimado de 12 dias de armazenamento, elevando a partir deste até os 21 dias. Apesar de se verificar essa elevação do $\mathrm{pH}$ nos peixes durante o período de armazenamento, o tratamento hidroalcoólico encontra-se dentro da média estabelecida pela legislação brasileira, sendo 6,5 na parte interna e 6,8 na parte externa da musculatura do pescado (BRASIL, 1997). O pH do peixe após a morte tende a diminuir pelo acúmulo de ácido lático, advindo da degradação das reservas de glicogênio e começa a se elevar, provavelmente, a partir de processos deteriorativos como autólise e hidrólise bacteriana. (TOLDRÁ, 2003).

Tabela 1. Médias de $\mathrm{pH}$ da interação entre os tratamentos contendo cloro e/ou extrato de Tingui e tempo de armazenamento em tilápias-do-Nilo

\begin{tabular}{lcccc}
\hline \multirow{2}{*}{ Tratamento } & \multicolumn{4}{c}{ Dias de armazenamento } \\
\cline { 2 - 4 } & 1 & 7 & 14 & 21 \\
\hline Tingui hidroalcoólico & $6,90^{\mathrm{Aa}}$ & $6,35^{\mathrm{Ab}}$ & $6,45^{\mathrm{Ab}}$ & $6,65^{\mathrm{Aa}}$ \\
Tingui aquoso & $6,50^{\mathrm{Ba}}$ & $6,40^{\mathrm{Aa}}$ & $6,45^{\mathrm{Aa}}$ & $6,37^{\mathrm{Ba}}$ \\
Cloro & $6,37^{\mathrm{Ba}}$ & $6,45^{\mathrm{Aa}}$ & $6,61^{\mathrm{Aa}}$ & $6,40^{\mathrm{Ba}}$ \\
\hline
\end{tabular}

Médias seguidas de letras iguais, maiúsculas nas colunas e minúsculas nas linhas, não diferem entre si pelo teste Scott-Knott $(\mathrm{p}>0,01)$.

Os peixes tratados com Tingui aquoso e cloro não apresentaram variações de $\mathrm{pH}$ na musculatura durante o período de armazenamento, além de obterem menores valores de $\mathrm{pH}$ aos 21 dias, como observado anteriormente. Isso pode ser importante para a prolongação da qualidade do pescado, pois quando o $\mathrm{pH}$ começa a se elevar pode estar ocorrendo decomposição de aminoácidos e desaminação oxidativa da creatinina, amônia, formando um meio favorável ao crescimento de bactérias, causando alterações indesejáveis no pescado (PEREIRA et al., 2001).

As bases nitrogenadas voláteis totais (BNVT) no pescado foram influenciadas pela interação $(p<0,01)$ entre os tratamentos e o tempo de armazenamento. As médias de BNVT nos peixes variaram conforme os tratamentos e o tempo de armazenamento (Tabela 2). Pode-se observar que durante o período de armazenamento os valores de BNVT aumentaram nos peixes tratados com Tingui hidroalcoólico e cloro aos 21 dias. 
Rev. Bras. Saúde Prod. Anim., Salvador, v.17, n.4, p.763-771 out./dez., 2016 http://www.rbspa.ufba.br

Os peixes tratados com extrato de Tingui aquoso mantiveram as BNVT estáveis durante todo o período de armazenamento e com menores valores em relação aos peixes dos outros tratamentos, aos 21 dias. Apesar das variações observadas, todos os peixes, ao final do armazenamento, mantiveram-se abaixo do limite estabelecido pela legislação brasileira que é de $30 \mathrm{mg}$ de N/100g de carne (BRASIL, 1997).

Tabela 2. Médias de bases nitrogenadas voláteis totais (BNVT) da interação entre a utilização de cloro ou extrato de Tingui e tempo de armazenamento em tilápias-do-Nilo

\begin{tabular}{lcccc}
\hline \multirow{2}{*}{ Tratamento } & \multicolumn{4}{c}{ Dias de armazenamento } \\
\cline { 2 - 5 } & 1 & 7 & 14 & 21 \\
\hline Tingui hidroalcoólico & $8,10^{\mathrm{Aa}}$ & $7,71^{\mathrm{Aa}}$ & $8,73^{\mathrm{Ba}}$ & $11,92^{\mathrm{Bb}}$ \\
Tingui aquoso & $7,60^{\mathrm{Aa}}$ & $6,45^{\mathrm{Aa}}$ & $7,02^{\mathrm{Aa}}$ & $7,14^{\mathrm{Aa}}$ \\
Cloro & $6,84^{\mathrm{Aa}}$ & $7,02^{\mathrm{Aa}}$ & $7,33^{\mathrm{Aa}}$ & $10,89^{\mathrm{Bb}}$ \\
\hline
\end{tabular}

Médias seguidas de letras iguais, maiúsculas nas colunas e minúsculas nas linhas, não diferem entre si pelo teste Scott-Knott $(\mathrm{p}>0,01)$.

A avaliação das BNVT está relacionada principalmente à quantidade de amônia no músculo dos peixes, provocada pela deterioração enzimática e bacteriana. Valores de 5 a 10mg N/100g de BNVT são relacionados a peixes de excelente frescor e 15 a $25 \mathrm{mgN} / 100 \mathrm{~g}$ para peixes com frescor razoável (OGAWA \& MAIA, 1999).

Delvaux Júnior (2011), trabalhando também com extrato de tingui, verificou bons resultados para BNVT em tilápias após 21 dias de armazenamento, obtendo valor médio máximo de $16 \mathrm{mg} \mathrm{N} / 100 \mathrm{~g}$. Em relação aos atributos da avaliação sensorial, a aparência e a aceitação geral foram influenciadas somente pelos tratamentos, o aroma somente pelo tempo de armazenamento e a cor pelos tratamentos e tempo de armazenamento.

As médias das notas atribuídas à aparência, cor e aceitação geral nas tilápias-do-Nilo armazenadas por 21 dias, tratadas com o extrato de Tingui aquoso se mostraram superiores, apresentando preferência pelos provadores (Tabela 3). Entretanto, não houve rejeição dos peixes de todos os tratamentos, obtendo-se uma nota média mínima de 6,38, sendo esta relacionada sensorialmente com o parâmetro gostei ligeiramente.

Tabela 3. Médias de notas atribuídas a aparência, cor, aroma e aceitação geral em tilápiasdo-Nilo tratadas com cloro e/ou extrato de Tingui, armazenadas por 21 dias

\begin{tabular}{lcccc}
\hline Tratamento & Aparência & Cor & Aroma & Aceitação geral \\
\hline Tingui hidroalcoólico & $6,58^{\mathrm{B}}$ & $6,88^{\mathrm{B}}$ & $7,03^{\mathrm{A}}$ & $6,84^{\mathrm{B}}$ \\
Tingui aquoso & $7,62^{\mathrm{A}}$ & $7,08^{\mathrm{A}}$ & $7,13^{\mathrm{A}}$ & $7,61^{\mathrm{A}}$ \\
Cloro & $6,38^{\mathrm{B}}$ & $6,54^{\mathrm{B}}$ & $7,04^{\mathrm{A}}$ & $6,64^{\mathrm{B}}$ \\
\hline \multicolumn{2}{l}{ Médias seguidas de letras iguais na coluna não diferem entre si pelo teste Scott-Knott $(\mathrm{p}>0,05)}$.
\end{tabular}

Médias seguidas de letras iguais na coluna não diferem entre si pelo teste $\operatorname{Scott}-\operatorname{Knott}(\mathrm{p}>0,05)$. 
Rev. Bras. Saúde Prod. Anim., Salvador, v.17, n.4, p.763-771 out./dez., 2016 http://www.rbspa.ufba.br

No decorrer do tempo de armazenamento, houve diminuição das notas atribuídas pelos provadores para aroma e cor (Figura 2). Rodrigues (2008) verificou que os atributos aparência, cor, aceitação e aroma obtiveram notas decrescentes do $8^{\circ}$ ao $15^{\circ}$ dia para a tilápia-do-Nilo estocada em gelo, e de acordo com o resultado da análise sensorial, as amostras foram rejeitadas após 15 dias armazenamento.

Yasmin et al. (2001), que observaram $28,4 \mathrm{mg} \mathrm{N} / 100 \mathrm{~g}$ em tilápia armazenada

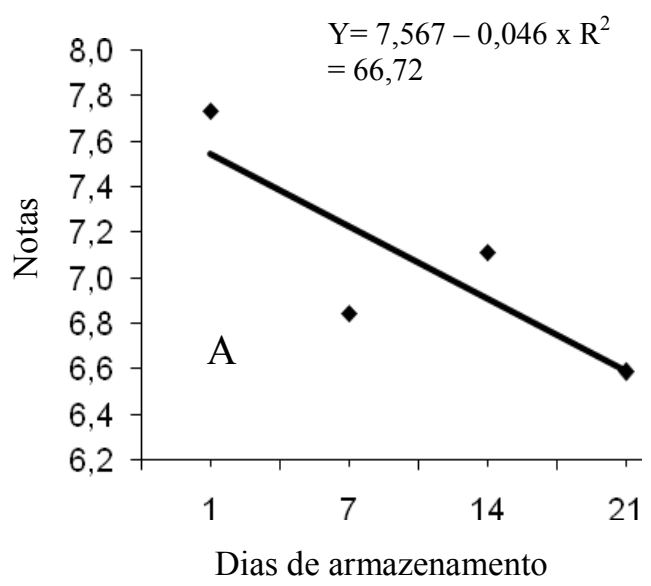

em gelo aos 16 dias, foi considerada aceitável sensorialmente, mas com sinais claros de degradação e aos 18 dias o pescado foi rejeitado apresentando $35,2 \mathrm{mg} \quad \mathrm{N} / 100 \mathrm{~g}$. Esse fato foi acompanhado pelo desenvolvimento de microrganismos. Delvaux Júnior (2011) também observou pequeno aumento da contagem de microrganismos em tilapias tratadas com extrato de tingui, entretanto os peixes encontravam-se em bom estado de conservação após 21 dias de armazenamento em gelo.

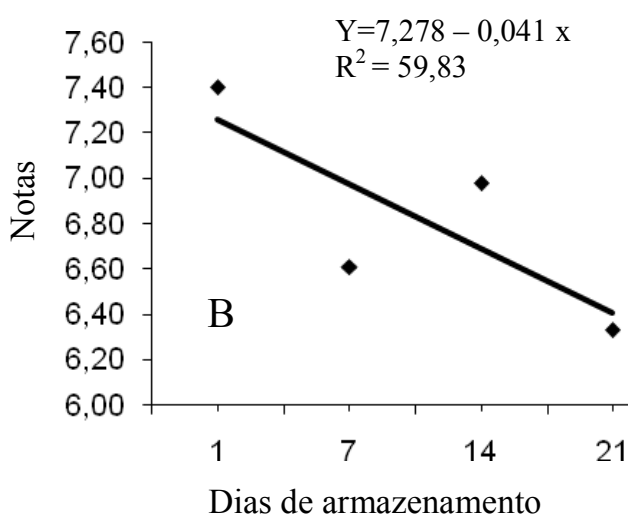

Figura 2. Análise sensorial para os atributos, aroma (A) e cor (B) em tilápias-do-Nilo tratadas com cloro e/ou extrato de Tingui, durante 21 dias de armazenamento

Todos os peixes armazenados em gelo apresentavam bom estado de conservação após 21 dias, indicando que os processos utilizados durante o processo de abate foram satisfatórios para um maior tempo de entrada no rigor mortis, garantindo menores alterações degradativas no pescado durante o período de armazenamento. Em relação aos extratos utilizados, o de tingui aquoso mostrou-se mais eficiente durante 21 dias, não sendo observadas alterações nos parâmetros avaliados durante o armazenamento, garantindo a manutenção da qualidade do pescado.

\section{AGRADECIMENTOS}

Ao Centro Integrado de Recursos Pesqueiros e Aquicultura do Gorutuba (CODEVASF) e a Fundação de Amparo à Pesquisa do estado de Minas Gerais (FAPEMIG). 
Rev. Bras. Saúde Prod. Anim., Salvador, v.17, n.4, p.763-771 out./dez., 2016 http://www.rbspa.ufba.br

\section{REFERÊNCIAS}

BITO, M.; YAMADA, K.; MIKUMO, Y.; AMANO, K. Studies on rigor mortis of fish - I. Difference in the mode of rigor mortis among some varieties of fish. By modified cuttingns methods. Bulletin of Tokai Regional Fisheries Research Laboratory, v.109, p.89-96, 1983.

BOYD, N.S.; WILSON, N.D.; JERRETT, A.R.; HALL, B.I. Effects of brain destruction on post harvest muscle metabolism in the fish kahawai (Arripis trutta). Journal of Food Science, v.49, p.177-179, 1984.

BRASIL. Ministério da Agricultura e do Abastecimento. Secretaria Nacional de Defesa Agropecuária. 1997. Decreto n³0691 de 29/03/52. Regulamento da Inspeção Industrial e Sanitária de Produtos de Origem Animal. Brasília DF.

$<$ http://pt.scribd.com/doc/3194328/RIIS POA $>$. Acesso em: 2 ago. 2013.

COÊLHO, A.A.M. Análise inseticida de extratos de plantas do bioma Cerrado sobre triatomíneos e larvas de Aedes aegypti. 2006. 138p. Dissertação (Mestrado em Ciência de Saúde) - Universidade de Brasília, Brasília, Distrito Federal.

CONTRERAS-GUZMÁN, E.S. Bioquímica de pescados e derivados. Jaboticabal: FUNEP, 1994. 409p.

DELVAUX JUNIOR, N.A. Avaliação da conservação da tilápia-do-Nilo submetida previamente ao abate ao extrato de tingui. 2011. 74p.

Dissertação (Mestrado em Zootecnia) Universidade Estadual de Montes Claros, Janaúba, Minas Gerais.
DUTCOSKY, S.D. Análise sensorial de alimentos. Curitiba: Champagnat, 1996, 123p.

FRANCO, B.D.G.M; LAMDGRAF, M. Microbiologia dos alimentos. São Paulo: Atheneu, 2003. 182 p.

HOWGATE, P. Determination of total volatile bases. Torry Research Station, Aberdeen: Aprendix , 1976.

MACEDO, M.C.; SCALON, S.P.Q.; SARI, A.P.; SCALON FILHO, H.; ROSA, Y.B.C.J.; ROBAINA, A.D. Biometria de frutos e sementes e germinação de Magonia pubescens ST.Hil (sapindaceae). Revista Brasileira de Sementes, v.31, n.2, p.202-211, 2009.

MENDES, J.M.; INOUE, L.A.K.A.; JESUS, R.S. Influência do estresse causado pelo transporte e método de abate sobre o rigor mortis do tambaqui (Colossoma macropomum). Brazilian Journal of Food Technology, v.18, n.2, p.162-169, 2015.

NEIVA, C.R.P. Valor agregado e qualidade do pescado. Revista

Panorama da Aquicultura, v.12, n.73, p.46-47, 2002.

OGAWA, M.; MAIA, E.L. Manual de pesca. São Paulo: Varela, 1999. p.175187.

OLIVEIRA, E.R.N. Deterioração do frescor. Apostila da disciplina de qualidade do pescado. Toledo, 2004.

PEDRAZZANI, A.S.; MOLENTO, C.F.M.; CARNEIRO, P.C.F.; CASTILHO, M.F. Senciência e bemestar de peixes: uma visão de futuro do mercado consumidor. Revista

Panorama da Aquicultura, v.102, p.24-29, 2007. 
Rev. Bras. Saúde Prod. Anim., Salvador, v.17, n.4, p.763-771 out./dez., 2016 http://www.rbspa.ufba.br

PEREIRA,W.D.; ATHAYDE, A.H.; PINTO, K.P. Avaliação da qualidade de peixes comercializados na cidade de Maceió-AL. Higiene Alimentar, v.15, n.84, p.67-74, 2001.

RODRIGUES, T.P. Estudo de critérios para avaliação da qualidade da tilápiado-Nilo (Oreochromis niloticus) cultivada; eviscerada e estocada em gelo. 2008. 116p. Tese (Doutorado em Medicina Veterinária) - Universidade Federal Fluminense - Faculdade de Medicina Veterinária, Niterói.

SAS Institute. SAS/STAT User's Guide. Versão 8. Cary, NC, 1999.

SILVA, I.G.; GUIMARÃES, V.P.; LIMA, C.G.; SILVA, H.H.G.; ELIAS, C.N.; MADY, C.M.; SILVA, V.V.M. NERY, A.P.; ROCHA, K.R.; ROCHA, C.; ISAC, E. Efeito larvicida e toxicológico do extrato bruto etanólico da casca do caule de Magonia pubescens sobre Aedes aegypti (Diptera, Culicidae) em criadouros artificiais. Revista de Patologia Tropical, v.32, p.73-86, 2003.

SILVA, M.L.; MATTÉ, G.R.; MATTÉ, M.H. Aspectos sanitários da comercialização de pescado em feiras livres da cidade de São Paulo, SP/Brasil. Revista do Instituto Adolfo Lutz, 67, n.3, p.208-214, 2008.

TOLDRÁ, F. Muscle foods: water, structure and functionality. Food Science Technology International, v.9, n.3, p.173-177, 2003.

VIEGAS, E.M.M.; PIMENTA, F.A.; PREVIERO, T.C.; GONÇALVES, L.U.; DURÃES, J.P.; RIBEIRO, M.A.R.; OLIVEIRA FILHO, P.R.C. Slaughter methods and fish meat quality. Archivos de Zootecnia, v.61, p.41-50, 2012.
YASMIN, L.; KAMAL, M.; AHMED, S.A.K.; AZIMUDDIN, K.M.; KHAN, M.N.A.; ISLAM, M.N. Studies on the Post-mortem Changes in Genetically Improved Farmed Tilapia (Oreochromis niloticus) During Ice Storage. Pakistan Journal of Biological Sciences, v.4, v.9, p.1144-1148, 2001.

Data de recebimento: 19/10/2015

Data de aprovação: 01/09/2016 